\title{
The Solution of the Overvoltage Damage for IMS's Microseismic Monitoring System
}

\author{
Chen Ruxiu, ${ }^{1,}$, Liao Hua ${ }^{2}$ \\ ${ }^{1}$ Department of Mechanical \& Electrical, Cotech Engineering Fuzhou CORP, Fuzhou, China \\ ${ }^{2}$ Department of Information, Hunan Shizhuyuan Nonferrous Metals CO, LTD, Chenzhou, China
}

Email address:

ruxiuchan@163.com (Chen Ru-xiu)

${ }^{*}$ Corresponding author

\section{To cite this article:}

Chen Ruxiu, Liao Hua. The Solution of the Overvoltage Damage for IMS's Microseismic Monitoring System. International Journal of Mechanical Engineering and Applications. Vol. 6, No. 4, 2018, pp. 98-103. doi: 10.11648/j.ijmea.20180604.12

Received: August 1, 2018; Accepted: September4, 2018; Published: October 15, 2018

\begin{abstract}
With the further development of digitized mine system construction, various kinds of communication, information, automatic and intelligent electronic equipment are widely used in mines. Due to the harsh underground environment of domestic (China) mines, various faults of electronic equipment occur frequently, such as dampness, dust pollution, burn damage, mechanical damage. This makes the system can not run stably and reliably. Especially the phenomenon of burning damage of electronic equipment. It is often large area damage when it happens, which seriously affects the safety production of enterprises. The IMS equipment of microseismic monitoring system that installed in Shizhuyuan Mine was burning damaged many times. Through the in-depth analysis and diagnosis of the failure of the IMS burning module and the overall microseismic monitoring system underground chamber, the fault (which is the system overvoltage) and its causes are found out. According to the reality condition of Shizhuyuan mine that how to prevent the overvoltage damage is systematic analysis and improvement. Than adopt effective measure and methods such as: prevention of overvoltage generation, cut off the intrusion pathway of overvoltage, choosing the surge protector reasonably with the insulation level of the system, switch to the right power supply plan and power supply facilities. These protective measures and methods comprehensively protect the safety of microseismic monitoring system equipment. After that, the microseismic monitoring system is successfully protected and no longer burned down. It successfully solves the problem of equipment burning damage of microseismic monitoring system, provides reliable guarantee for mine safety production. Shizhuyuan mine is a typical underground mining metal ore in China, the successfully solution of overvoltage damage provides a good demonstration for how to prevent mine electronic equipment underground from burning damage, It also provides more standardized and accurate requirements for the way and the protection of power supply system, and the laying of lines for a new projects.
\end{abstract}

Keywords: Microseismic Monitoring System, Protection, Overvoltage, Damage

\section{Introduction}

Since the Notice No. 23, No. 168 in 2010 and No. 108 in 2011 by the State Administration of Work Safety, the construction of the "six systems" of mine safety (it refers: 1 . Control and monitoring system for environment and equipments, 2. Personnel positioning system, 3. Emergency evacuation system, 4. Compress air for breath system, 5. Clean water supply for rescue system, 6. Telephone system) has been carried out in an all-round way $[1,2]$. At the same time, microseismic monitoring technology is widely used in underground engineering construction and mine ground pressure monitoring and slope safety monitoring, The on line dynamic monitoring and positioning characteristics provide good technical support for the early-warning of ground pressure monitoring, and have achieved remarkable effect [3-6]. It is gradually replacing the traditional portable acoustic emission instrument. The equipment of microseismic monitoring system is produced at domestic or abroad, but the domestic equipment is not mature enough [7-9]. The equipment of microseismic monitoring system used in some medium and large mines is basically imported from abroad. According to the investigation, most of the underground mine 
microseismic monitoring system and the "six systems" have achieved remarkable results in the initial stage of construction. But the working well life of the system is not long. There often break down and lose effectiveness, because of the difficulties to repair and the length restore period. The use of microseismic technology is seriously affected, and even the normal work safety of the enterprises is affected. Therefore, how to ensure the stable operation of monitoring system is the key to the application and popularization of microseismic monitoring technology.

The long-term work well and stable operation of microseismic monitoring system is a prerequisite for microseismic technology to play a positive role. It is of great value to probe into the causes of frequent failures of imported equipment in domestic mining enterprises and adopt effective prevention and control techniques. Because, First, ensure the stable operation of microseismic monitoring system, is provided strong material guarantee for safety management. Secondly, provide data source support for the application research of microseismic monitoring technology. Third, provide good experience for domestic independent research and development of this kind of equipment, and it is the basis experience for improving the stability of equipment. Fourth, the successful experience can be applied to other electronic information systems of mine enterprises, such as the "six systems" of underground mine, even for the safety protection of the on-line monitoring system of the tailing pond.

\section{Method}

The Hunan Shizhuyuan Nonferrous Metals CO., LTD (Abbreviation: Shizhuyuan mine) is one of the typical underground multiple metal mines in China. It is also one of the underground metal mines which introduced the microseismic monitoring technology earlier. The failure of the underground equipment in the IMS microseismic monitoring system is very common in China.

\subsection{Microseismic Monitoring System of the Shizhuyuan Mine}

The 30 channels digital microseismic monitoring system was first completed in the Shizhuyuan mine's LV490 metal mining area in 2008, which realized the real-time monitoring function of the ground pressure change and provided a powerful technical guarantee for the ground pressure management in the large mine-out areas and levers areas. Since microseismic monitoring technology has a full range of all-weather, real-time monitoring, high precision three-dimensional location of fracture source and other technologies, this monitoring technology has become the main means of monitoring the ground pressure of the Shizhuyuan mine. With the advance of the mining field in the southeast direction and the top-open of the large blasting in 2012, the high and large steep slopes and the upper part vertical suspended top in the eastern part of the Shizhuyuan mine area became the main problem of the ground pressure safety after that blasting. In order to better monitor the stability of high large steep slopes and vertical suspended top, the IMS microseismic monitoring system, which has a larger monitoring event level, is used in 2014.

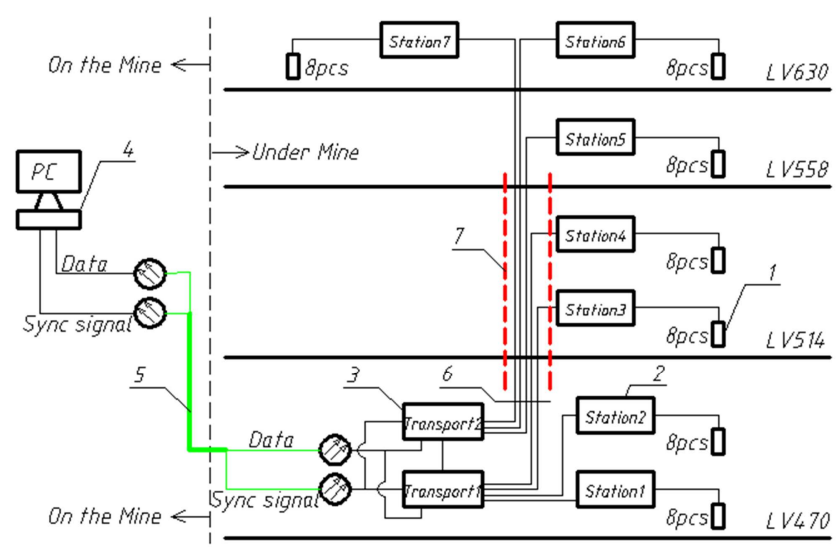

Figure 1. IMS System Architecture Diagram.

sensor 2, station 3, transport 4, server pc 5, optical cable 6, copper cable 7 , meter single shaft

The system architecture is shown in Figure 1: a total of 7 stations are arranged on 4 levels. Each station receives 8 sensors, total 56 channels. The system uses a star distribution to transmit data to the transmission port(modem) by DSL communication, and the data is uploaded to the server (the surface host) by the transmission port, and at the same time the server simultaneous signals are also transmitted through optical cables to the transmission port. The modem has the function of coupling the simultaneous signals to the DSL port connected to the station. The IMS station is composed of four modules: UPS, ADC, SP and DSL modem. All the sensors are connected to the ADC module. SP is responsible for collecting, triggering and controlling, and DSL modem is responsible for data transmission.

Fiber optic cables are used to connect the ground server and the underground transmission port, and different copper-core signal cables are used to connect the station to the transmission port and the sensor to ADC. There are instrument wells, traffic laneways or vertical boreholes between the different levels sections.

\subsection{IMS Equipment Failure Features}

Fault A: the system is normally used after the end of 2014. In Chinese New Year of 2015, during the Spring Festival mining equipments and fans must be power off, but the IMS monitoring system continue to run. Some IMS system stations of UPS and ADC modules can not be worked out when the power supply is started after the festival. The mine side also claimed that the power adapter of the "six systems" was damaged. It is overvoltage damage after identification, and system work well again after replacement adapter. Fault B: when a $10 \mathrm{KV}$ high voltage cable was laid through the LV558 microseismic chamber and the instrument well, in addition the cable was put on the equipment box directly. When the cable power failure, all the modules in the 558 chamber station were 
burned down and the transmission port of the LV470 chamber was burned down in time. Failure features such as Figure 2. Forcing the IMS microseismic equipments to stop running. Fault C: during the stop operation of the IMS system and $10 \mathrm{KV}$ cable is still next to the transmission cable, the interface on the transmission port also burned out, with the same as Figure 2 .

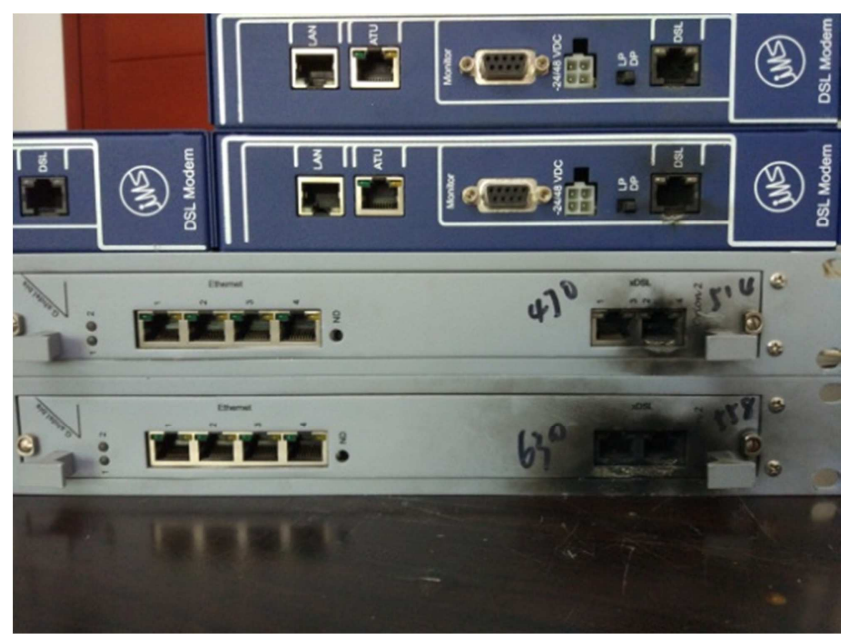

Figure 2. The Damage Equipments.

\subsection{Fault Analysis}

In the light of the damage caused by the IMS system equipment destroyed many times, in order to excavate the root of the failure of the system and prevent the occurrence of the accident, a comprehensive accident investigation and in-depth analysis were carried out in 2016. From the above three failures, the fault $\mathrm{B}$ and the fault $\mathrm{C}$ belong to the same type of fault.

The failure $\mathrm{A}$ is that IMS system UPS module, ADC module outside is in good condition, but can not work again. Then send back to the original factory maintenance. Through the original factory inspection, the report is the main chip burned. Fault analysis: First, the fault occurs when the time is after the rework, the mining equipment insulation reduce during humid environment and many leakage phenomena occur. Secondly, the equipment 220VAC power source is from a fire line and a null line on the power bus of the underground power system, a voltage regulator transformer and UPS. Third, be confirmed, underground power protective grounding system is TT modem (neutral point ungrounded system) [10, 11]. Comprehensive three points analysis can be obtained: fault $\mathrm{A}$ is the neutral point drift caused by neutral point ungrounded system [12], for example, the $\mathrm{N}$ point shown in Figure 3 is the neutral point position in the normal period. When the fault occurs, the position of the neutral point is drifting to N', resulting in the increase of the phase voltage. The maximum steady state overvoltage of the single phase short-circuit of the TT system is $1.732 \mathrm{U}$, the maxium transient overvoltage (high frequency oscillation, voltaic arc intermittent extinction and reburning) is $2.5 \mathrm{U}$ in the first time voltaic arc burning, and is up to $3.5 \mathrm{U}$ in voltaic arc again burning [13]. So 220VAC voltage supply direct come from two phases by TT system mode is easy to cause equipment damage due to overvoltage. This is the typical internal overvoltage caused by neutral offset, and it is also the fundamental reason for burning the IC inside the module.
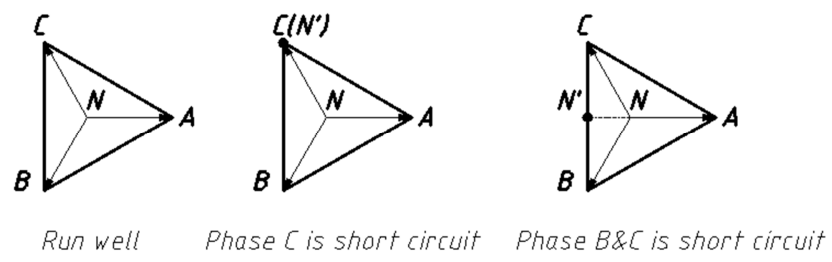

Figure 3. Voltage vector diagrams.

Fault B, We can clearly visible from picture in Figure 2 that the RJ45 interface of high voltage breakdown and blackening. The transmission port of LV470 and levels section DSL modem are the same. Combined with Figure 1, can found that the copper core cable between the modem and transmission ports passes through the instrument well, and there is no Figure 2 failure phenomenon before the $10 \mathrm{KV}$ cable laid in 2015. Once the $10 \mathrm{KV}$ cable insulation reducing or environmental changes, the electric faults such as leakage, flashover, short-circuit and other electrical failures occur, a strong electromagnetic field around the $10 \mathrm{KV}$ cable causes a high voltage near the conductor $[14,15]$. Although this type overvoltage is not like the lightning overvoltage, but the energy is large enough to burn the electronic equipment, IMS equipment in this system is caused by this induced overvoltage.

\subsection{Overvoltage Measure}

According to the above section analysis, the IMS system of Shizhuyuan mine has been burned many times with internal overvoltage and induced overvoltage. In view of the prevention and control of over-voltage hazards, the following strategies are usually adopted: First, to prevent over voltage come into being: use a reasonable scheme or system to eliminate overvoltage. Second, cut off the overvoltage transmission pathway: isolate overvoltage from the equipment. Third, to perfect the grounding system and to take effective protection measures to match the system Insulation level [16, 17].

Base on high reliability of the power supply of TT grounding system, this kind of power supply scheme is basically adopted in domestic mines. The solution of the offset of neutral point is to use a $380 / 220 \mathrm{~V}$ isolation transformer, using the characteristic of maintaining the balance of line voltage when the TT system is grounded, the original single-phase power supply is replaced by a two phase power supply, that is, the isolation transformer voltage of 380VAC side connection two phases of power system, the 220VAC side power supply with stable output is supplied to the monitoring equipment. The scheme greatly improves the reliability of power supply, and the grounding fault occurs in the underground power system. As long as the power supply 
system does not pull the brake, the transformer output of 220 VAC is stable.

The way to cut off the overvoltage transmission pathway and prevent overvoltage come into being is the most effective way to prevent induced overvoltage. For the inevitable $10 \mathrm{KV}$ high voltage cable in the instrument well, using the advantages of optical fiber resistance to strong electromagnetic interference, the common DSL communication mode of IMS system is changed to Ethernet communication mode. It does not induce high voltage on the optical fiber line, completely excision the generation and propagation of induction overvoltage, so as to ensure the safety of the equipment. In the system, the power supply and sensor are also connected to the equipment by copper-core cables, can not be replaced with optical cables. These are all possible and interfering factors to produce and conduct overvoltage. So cables laying must avoid power cable or high voltage cable as far as possible. When it is impossible to avoid laying such as parallel and vertical laying should be strictly observed the safety distance provided by the regulations or rules.

To adopt the lightning protection measures and reduce the insulation configuration, it is necessary to perfect the grounding system and select the appropriate surge protector. The grounding system underground chamber construction is shown in Figure 4. The underground monitoring chamber grounding system is composed of grounding device and grounding grid, and surge protection device. Doors and windows, railings, metal components, import and export protection pipe, metal case shell, equipment metal shell, cable shield layer, surge protector and so on are connected or welded with the shortest distance with equipotential bonding. Each part is connected to the same potential and is not connected in series. Equipotential bonding (grounding grid) is the main device to ensure that equipment is free from overvoltage damage.

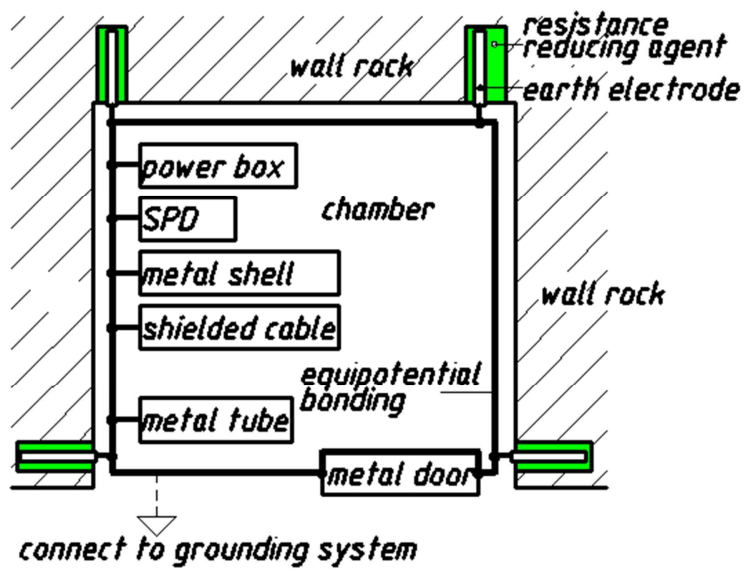

Figure 4. Earthing System Schematic.

The repeated grounding device for underground monitoring chamber can be buried in the chamber around the chamber, fill the ground pole, fill the drop resistance agent in the hole, and weld the ground electrode directly on the equipotential line, the equipotential row must be connected with the underground main grounding grid reliably [18], such as the Figure 4. The underground chamber and the surrounding of the mine are composed of high resistivity rock. The power supply system uses neutral point ungrounded form, the leakage current is very small, the chamber set up equal potential connection, the equipment and personnel have safety protection. The grounding device is designed to release the energy of the overvoltage by the surge, and the repeated grounding resistance has no specific resistance. Under some conditions do be lower the grounding resistance.

Surge protector can effectively absorb the huge burst of energy, reduce the insulation configuration of the main equipment, should be based on the type of overvoltage reasonable selection of surge protector. Generally, the underground monitoring chamber is shown as the internal overvoltage. It is suggested to install a class I unit in the power transformer 380VAC side nearly, and release the energy in the monitoring chamber by the installation class II / III / IV units in the monitoring chamber. Class I surge protection device: nominal discharge current $\mathrm{In} \geq 60 \mathrm{KA}$, protection level $\mathrm{Up} \leq 2.5 \mathrm{KV}$. Class II device: nominal discharge current In $\geq 20 \mathrm{KA}$, protection level $\mathrm{Up} \leq 1.2 \mathrm{KV}$. Set class III Protection at the equipment end: nominal discharge current $\mathrm{In} \geq 10 \mathrm{KA}$, protection level $\mathrm{Up} \leq 1.0 \mathrm{KV}$, and set class IV level protection on the side of the sensor or the side of the communication line, the standard of protection: standard the discharge current In $\geq 5 \mathrm{KA}$, the voltage level is according to the rated voltage of the equipment $[19,20]$, and the network data is equipped with a special lightning protection device.

\section{Result}

The microseismic system of the Shizhuyuan mine has set up four levels section of 470/514/558/630. After the failure, the rectification measures are: 1) The power supply of the microseismic monitoring system add a set the 380/220VAC isolation transformer. 2) And the grounding system has been set up. The grounding system is designed and constructed in accordance with the pattern plate in Figure 4, of which levels 514/558 monitoring chamber is connected with the existing grounding grid. 3) The system adds a surge protector, and the configuration is as follows: the class II protector is set in the power box of the microseismic system, and the class IV to device - safety isolation module is reconfigured between sensors and ADC. At the same time, it is suggested to set up class I protection module in the low voltage $(380 \mathrm{~V})$ main power transformer. 4) The data transfer cables to all fiber transmission. 5) The cable laying in the tunnel is arranged according to the regulations or rules.

After the rectification and construction of the IMS microseismic monitoring system in Shizhuyuan mine, the system operates normally. The failure of equipment burn out does not happen again.

\section{Discussion}

The safety "six systems " of mine and the microseismic monitoring system equipments in the domestic mines is 
frequent failure, the destruction of equipment can not be repaired and run in time, the service life is short, even the system is paralyzed in short time. It seriously reduces the actual effect of the equipment operation, causes the dangerous condition of the ground pressure safety monitoring in the interruption, and various scientific research advance is blocked. In the mining enterprises. The voice "more advanced and more enervated to be used in the rough mines, and the more simple traditional monitoring means shall be used in the mining" of conservative ideas that hinders the promotion and development of the new technology. Even more, science and technology are suspected of corruption. There are three reasons for such a situation.

First, microseismic monitoring system equipment is a set of system special equipment developed by multidisciplinary, in addition to the most important processes, such as Mining, Rock Mechanics, Geophysics, Geology, and so on, the system at least covers Mechanics, Materials, Electronics, Electrology, Communications, Computer Science, and Software. Also, The project approval and selection of equipment for the application of microseismic monitoring system lacks sufficient and systematic communication; it often occurs serious stealth errors, and it may not get a professional solution for a long time and circulate the same mistakes. This is the typical disadvantage of the closed scientific research field in Chinese.

Secondly, Chinese mines environmental condition is different from foreign, the introduction of foreign advanced equipment, often neglect the harsh degree of domestic mining environment. When the foreign import equipment is selected in the system, the suppliers often choose the system framework and components according to the foreign mine standards. When they are applied to the Chinese mines, the sudden failure occurs easily. The foreign suppliers can not solve the problems outside the equipment. The system has similar problems after the replacement of the equipment. The domestic actual developer does not know the production process and the application environment completely, according to the functional requirement design and selection, equipment can not pass the mine harsh environment and the long time test; the system equipment lacks for the whole equipment to carry on the planning and design, exists the original design and the assembly deficient, especially the equipment of the "six systems ".

Third, the domestic mining conditions are hard, all kinds of professionals and young people are reluctant to serve the mining enterprises. The professional and technical level of employees is low, and the age aging is poor acceptance. The technical strength of equipment usage, operation, management and maintenance is rather weak. After the completion of the system construction, it is a serious psychological burden to the actual use or the operator, and it produces the fear of the inaction, even if the operation is improper or unfamiliar, the first reaction on they mind is the system failure, so they are waiting for the external resources to solve the problem, which is common in the Chinese mining enterprises. This phenomenon is not conducive to the promotion of advanced equipment and methods, so the lack of scientific and technological personnel in mines, fault has become a constraint on the development of modern mine science and technology.

\section{Conclusion}

Through the analysis of the actual case of the equipment failure of the IMS microseismic monitoring system and the implementation effect of the solution, and the deep discussion of the roots behind the fault, the following suggestions are put forward.

Firstly, the overvoltage measure scheme of microseismic monitoring system should be popularized as the safety standard of electronic information system in mining enterprises. The $380 / 220$ VAC isolation transformer is used to power supply. The construction of grounding system is perfected. A reasonable surge protector is selected to match the insulation level of the system. The production and introduction of interference are reduced in design and selection.

Second, scientific research institutions and production enterprises should think highly and strengthen the long-term construction of their own scientific and technological talents, promote multidisciplinary, cultivate interdisciplinary young technicians, help the development modern mines, and enhance their competitiveness.

\section{References}

[1] XUN Xue-mei, CHEN Ri-hui. Construction of Six Safe Danger Hedge System in Dahongshan Copper Mine [J]. China Mine Engineering (in Chinese), 2016, 45(6):12-15.

[2] WU Di-wen, KOU Xiang-yu. Research on Merge Construction of Digital Mine and "Six System" [J]. Mining R \& D(in Chinese), 2016, (10):120-123.

[3] IA Jing. Application Research on Microseismic Monitoring Technology in Coalmine Water Control [J]. Coal and Chemical Industry(in Chinese), 2017, 40(1):16-20.

[4] CHEN Xiang-xiang, SU Zhen-hao, LI Lin-fei, et al. Application of Microseismic Monitoring System in a Tungsten Mine [J]. China tungsten Industry(in Chinese), 2016, 31(4):26-31.

[5] WANG Xu, TANG Shao-hui, GUO Xiao-qiang. Application of Microseismic monitoring Technology in Complex Goaf Group [J]. Mining R \& D (in Chinese), 2017, 37(4):1-4.

[6] CHEN Hai-xia. Application of Microseismic Monitoring Technique on High Rock Slope Stability of Highway [J]. China Harbour Engineering (in Chinese), 2017, 37(6):81-86.

[7] ZHANG Chu-xuan, LI Xi-bing, DONG Long-jun, et al. Analysis of microseismic activity parameters pre-and post roof caving and early warning [J]. Chinese Journal of Rock Mechanic and Engineering (in Chinese), 2016, 35(supp 1):3214-3221.

[8] MA Tian-hui, TANG Chun-an, TANG Lie-xian, et al. Mechanism of rock burst forcasting based on micro-seismic monitoring technology [J]. Chinese Journal of Rock Mechanic and Engineering (in Chinese), 2016, 35(3):470-483. 
[9] LYU Lei, ZHANG Jiao-fu, ZHU Quan-jie, et al. Construction phase space and determination of chaotic attractor dimension for time series of mine microseismic. [J] Journal of Safety Science and Technology. 2016, 12(2), 27-32

[10] LUO Yu-hui. Analysis of Neutral Grounding Mode in Power System [J]. New Technology \& New Products of China (Chinese), 2017, 7:21-22.

[11] YAO Jin-han. Analysis of the Cause of Grounding Transformer Burnout and the Advantages \& Disadvantages of Using Grounding Transformer [J]. New Technology \& New Products of China (Chinese), 2017, 1:147-148.

[12] LIU Jin-xian. Analysis of Neutral Voltage Displacement Solution for Mine Distribution Network [J]. Electronic Test (Chinese), 2016, 12:145-146.

[13] Hou Yi-ming, Yu Hui, Wang Xi-wei. Grounding Mode and Overvoltage Protection of Distribution System [M] Asian Power Quality Alliance China cooperation group editor, Beijing, China Electric Power Publishing House, 2015, No.1 version.

[14] ZHENG Xue-lin. Analysis of Lightning Induced Overvoltage Characteristics of $10 \mathrm{kV}$ Distribution Lines [J]. Technological Development of Enterprise (Chinese), 2016, 35(2):86-87.

[15] XIA Neng-hong, GUO Jie, TIAN Meng-lin. Analysis of Induced Overvoltages in Low-Voltage Installations During Direct Strikes to LPS of Building [J]. Insulators and Surge Arresters (Chinese), 2017, 5(279):47-53.
[16] LI Yong-pan. The Protection for Single Phase Grounding Fault of Mine Power System [J]. Modern Mining (Chinese), 2017, 2:211-212, 214.

[17] REN Yuan-hui. Fault Prevention and Selection of Electrical Protective Device in Low Voltage Distribution System [J]. Building Electricity (in Chinese), 2016, (7):3-10.

[18] People's Republic of China Ministry of housing and urban rural development approval, China Coal Construction Association. GB50070-2009, Design code for mine electric power [S] Beijing: China planning Publishing House, 2009.

[19] People's Republic of China Ministry of housing and urban rural development approval, Editor in chief China Machinery Industry Federation. GB50057-2010, Design code for protection of structures against lightning [S] People's Republic of China Ministry of construction, People's Republic of China State Administration of quality supervision, inspection and Quarantine jointly issued, Beijing, 2010.

[20] People's Republic of China Ministry of housing and urban rural development approval, Editor in chief Sichuan Department of housing and urban and rural construction. GB50343-2012, Technical Code for Protection of Building Electronic Information System Against Lightning [S] People's Republic of China Ministry of construction, People's Republic of China State Administration of quality supervision, inspection and Quarantine jointly issued, Beijing, 2012. 